\title{
Personality is associated with dominance in a social feeding context in the great tit
}

\author{
Nehafta Bibi ${ }^{\text {a }}$, Yusheng Wei ${ }^{\mathrm{b}}$, Hongwei Xu $^{\mathrm{c}}$, Jingnan Liang ${ }^{\mathrm{a}}$, Ijaz Hussain $^{\mathrm{d}}$, \\ Munawar Saleem Ahmad ${ }^{\mathrm{e}}$ and Haitao Wang ${ }^{\mathrm{a}, \mathrm{b}, *}$ \\ a Jilin Engineering Laboratory for Avian Ecology and Conservation Genetics, School of Life \\ Sciences, Northeast Normal University, Changchun, P.R. China \\ b Jilin Key Laboratory of Animal Resource Conservation and Utilization, Northeast Normal \\ University, 5268 Renmin Street, Changchun, P.R. China \\ ${ }^{c}$ Ministry of Education Key Laboratory of Vegetation Ecology, School of Life Sciences, \\ Northeast Normal University, Changchun, P.R. China \\ ${ }^{d}$ Department of Statistics, Quaid-i-Azam University, Islamabad, Islamabad 44040, Pakistan \\ ${ }^{\mathrm{e}}$ Department of Zoology, University of Swabi, Swabi 22621, Pakistan \\ *Corresponding author's e-mail address: wanght402@nenu.edu.cn
}

Received 22 December 2018; initial decision 24 January 2019; revised 19 August 2019; accepted 20 August 2019; published online 9 October 2019

\begin{abstract}
Despite the growing interest in consistent individual differences in behaviour (animal personality), the influence of social context on different behavioural types remains poorly understood. The suite of correlated behaviours within and across contexts is called behavioural syndromes. Most personality studies have investigated consistent individual behavioural types and their consequences in a asocial context, however few studies have considered the influence of social context on individual behaviour. In addition, the evolutionary and ecological consequences of personality differences in social context remain unknown. In the present study, we confirm individual personality in Great tits (Parus major) using room exploration and neophobia tests. As a result of these two tests, repeatability and correlational structure of two personality traits were investigated. Additionally we assessed the extent to which personality influences dominance in a social feeding context.

Great tits remained consistent in their personality traits (exploration and neophobia). Individuals who explored a novel environment faster also approached a novel object faster, while those who spent more time exploring a novel environment were also slower to approach a novel object. In a social feeding context personality was linked to dominance: with proactive individuals being more likely to be dominant. Our result provides evidence of the importance of social context in a wild population of birds and may have fitness consequence, both for focal individuals and their conspecifics.
\end{abstract}




\section{Keywords}

Neophobia, exploration, Great tit, personality, novel object, social context.

\section{Introduction}

Individuals within a population often differ consistently in their behavioural tendencies across time and contexts (Wilson, 1998; Sih et al., 2004a,b; Réale et al., 2007). Behavioural variation within and between populations has recently turned towards understanding individual consistency of behaviours which can be addressed both within the same behavioural trait and between different behaviours (Dingemanse et al., 2010; Dingemanse \& Wolf, 2010). These correlated behaviours between individuals are commonly termed as behavioural syndromes (Dingemanse et al., 2010, 2012; Dingemanse \& Dochterman, 2013). Behavioural syndromes have stimulated the behavioural ecologists to consider animal behaviour from a multivariate rather than univariate perspective (Sih et al., 2003, 2004a,b).

In nonhuman animals, personalities have important ecological and evolutionary consequences (Smith \& Blumstein, 2008). It is challenging to disentangle the ultimate and proximate mechanisms beyond the emergence of non-independence between such seemingly different behavioural traits as foraging activity in a novel environment, risk-taking in the presence of predators and aggression towards conspecifics (Sih et al., 2004a,b; Sih \& Bell, 2008). Such coupled behaviours set up important evolutionary constraints because they infer limited phenotypic plasticity: individuals cannot optimally choose their responses in each ecological or social situation that they are confronted with in their life (Wilson, 1998). If behaviours are linked, bold individuals will tend to display aggressive responses towards conspecifics as well as towards predators, even if the adaptive values of these responses are opposing. Accordingly, behavioural syndromes may drive life-history trade-offs and ultimately determine fitness that can be achieved in different environments (Sih et al., 2004a,b; Sih \& Bell, 2008).

Previous empirical investigations revealed that animal personalities and behavioural syndromes co-vary with ecological conditions, depending on the state of the individuals, and can be maintained by frequency-dependent selection (Garamszegi et al., 2012; Wolf \& Weissing, 2012; Sih et al., 2015). For instance, in fishes, individual boldness and aggressiveness are often positively correlated (constituting a behavioural syndrome), but the strengths 
and structures of this syndrome co-vary on the prevailing predation regime (Huntingford, 1976; Dingemanse et al., 2007; Brydges et al., 2008; Archard \& Braithwaite, 2011).

Personality studies have been conducted both in asocial (Dingemanse \& de Goede, 2004) and social context (Verbeek et al., 1996). However social association is worth investigating because social context is an important modifier of an individual's behavioural response (Koolhaas et al., 1999; Van den Bos et al., 2013), and it may either facilitate or delay an individual's behavioural response (Webster \& Ward, 2011). In recent years a considerable amount of work has been done on the relationship between personality and several aspects of social behaviour on various organisms, such as, fish (Pike et al., 2008; Colléter \& Brown, 2011; Jolles et al., 2017) birds (Kurvers et al., 2009, 2010; Aplin et al., 2013; Sasaki et al., 2018) and mammals (Michelena et al., 2008). Taken together, these studies provide strong evidence that social relations can be targets of selection and may have important fitness consequences, both for individuals and for their social-foraging associates.

In a social context, the behaviour of an individual is likely to be influenced by the behaviour of other conspecifics. Therefore, in highly social species, the results obtained from asocial personality tests might not reflect individual behavioural responses in natural contexts. Consequently, misleading conclusions might be drawn from studies restricted to asocial contexts.

For instance, animals that forage in groups to reduce predation risks might respond to risk-taking assessments very differently when they are isolated, perhaps because of an elevated fear brought on by isolation. Consequently, social isolation has been found to cause behavioural inhibition in social species (Krause \& Ruxton, 2002). Previous studies have shown that in social species, the influence of social context on individual behaviour is based on several characteristics, including foraging strategy in house sparrows (Passer domesticus) and vigilance level in redshanks (Tringa totanus) (Vickery et al., 1991; Cresswell, 1994). Previous studies have also suggested that the presence of a partner influences the behaviour of a focal individual. Not only can the presence of conspecifics affect foraging strategies of individuals in general but it can also influence individuals differently, depending on their personality: Marchetti \& Drent (2000) showed that individual great tits, of different exploration types differed in their tendency to copy a tutor's foraging decision. Besides effects on foraging decisions, the presence of conspecifics can have impacts on perceived predation risk (Clutton-Brock 
et al., 1999; Lima \& Bednekoff, 1999; Krause \& Ruxton, 2002) and/or food competition (Janson \& Goldsmith, 1995). Great tits probably affect the risktaking behaviour of individuals differently (van Oers et al., 2005).

The great tit is a secondary cavity-nesting, territorial passerine and its distribution ranges throughout Europe and large parts of central and south Asia, except for in the most alpine and harsh areas (Julliard et al., 2006; Birds Life International, 2015). Male great tits, differ consistently in whole suits of correlated traits, with more aggressive individuals also tending to be more explorative towards novel objects and novel environments than less aggressive ones (Verbeek et al., 1996). The aim of the present study is to test whether personality is associated with dominance in a social feeding context in the great tit. We examined the repeatability and correlational structure of two behavioural traits (exploratory behaviour and neophobia) in male great tits. We expected that great tits that explored novel environments more quickly and superficially to be the ones that explored the novel object more quickly. Following life history theory (Biro \& Stamps, 2008), we predicted that proactive individuals should have preferential access to food through dominance.

\section{Methods}

\subsection{Study site and housing}

In this study, we examined 24 male great tits caught with trapping cages in Jilin City and the surrounding areas in Jilin Province, P.R. China, between October and December 2017. Individual from single population of great tits were transported to the laboratory within four hours. Upon arrival to the research laboratory, we kept individuals under a 12:12 hour photoperiod in $0.9 \times 0.4 \times 0.5 \mathrm{~m}$ cages, each with compact lower and upper surfaces, lateral and back walls, a wire-netting anterior and three small perches (Verbeek et al., 1996). The birds were provided with worms, commercial seed mixtures, sunflower seeds and water ad libitum. Sex of all the birds was determined following Svensson (1992) and only male birds were included in the study because males are generally more aggressive than females, this behavioural characteristics may also affect dominance (Verbeek et al., 1996). Exposure to humans was minimized, and the individuals were left undisturbed overnight. The individuals were released back to their natural habitat after completion of the experiment. 


\subsection{Testing personality traits}

\subsubsection{Exploratory behaviour and neophobia}

In line with former personality studies, individual exploratory behaviour was examined in an observation room $(4.0 \times 2.4 \times 2.3 \mathrm{~m})$ (Dingemanse et al., 2002; Drent et al., 2003; van Oers et al., 2004a). After arrival at the laboratory; we tested each individual for exploratory behaviour between 09:00 and 14:00 hours the following morning under an artificial light closely resembling natural light. Individuals were deprived of food $2 \mathrm{~h}$ prior to the start of the trial to provide motivation to explore for food. We placed five artificial wooden trees within the room, and individual cages were darkened with a black curtain. Individuals were introduced to the room without handling by opening a sliding door, switching on the light and slightly lifting the black curtain (Dingemanse et al., 2002). Experimental birds were observed behind a one-way observation screen and their behaviour was recorded for two minutes when the trial was terminated. Later, these video recordings were used to analyse the details of exploratory behaviour. The time to reach four out of the five trees was used as a measure of exploratory behaviour (van Oers et al., 2005). We assigned a maximum latency of $120 \mathrm{~s}$ to individuals who did not visit four different trees within $2 \mathrm{~min}$. We repeated the trial one week later to determine the repeatability of exploratory behaviour (Figure 1).

Reluctance to feed in the presence of a novel object is called neophobia (Boissy, 1995). Birds were deprived of food and water for 90 min prior to the test (Beránková et al., 2015). The neophobia trial was performed in the birds' home cages $(0.9 \times 0.4 \times 0.5 \mathrm{~m})$; we returned the familiar plate containing the millet mixture and worms but included a novel object inside the plate (Beauchamp, 2002; van Oers et al., 2004b). Within two trials of an asocial context, a pink ball and penlight battery $(10-\mathrm{cm}$ diameter and 10-cm height) were used as novel objects (Moretti et al., 2015). Feeding

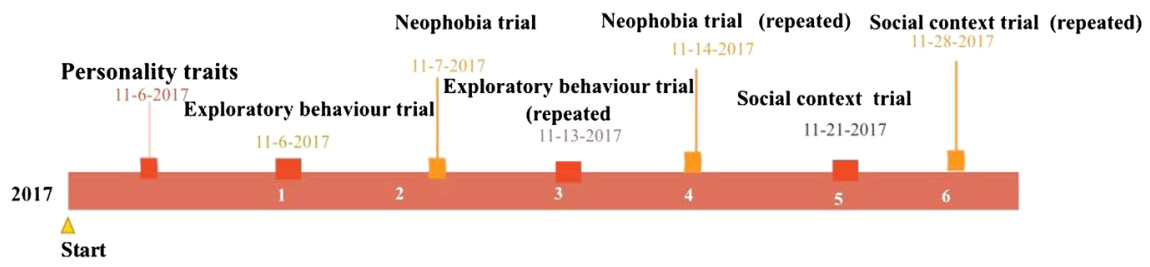

Figure 1. Timeline of the study. 
latency in the presence of the novel object was recorded for 2 min. Individuals who did not feed within 2 min were assigned a maximum latency of $120 \mathrm{~s}$ and their trials were terminated. A video camera was used to record the experimental birds, and an observer was hidden behind a one-way observation screen to observe the trials. All observations were carried out by the same observer to avoid biases. The video recordings were later analysed for latency to feed in the presence of a novel object (van Oers et al., 2004a; Schuett \& Dall, 2009; David et al., 2011). For all analyses, the mean of all the recorded variables were used (William et al., 2012) (Figure 1). Based on these two tests (exploratory behaviour and neophobia) individuals were categorized as either proactive or reactive following former studies (Verbeek et al., 1996).

\subsubsection{Social feeding context trial and social dominance}

Social feeding context trials were conducted (after one week of the neophobia test) between 09:00 and 13:00 after food deprivation for 90 min (Beránková et al., 2015). We returned the food plate containing a millet mixture and worms to each dyad (Beauchamp, 2002; van Oers et al., 2004b). The size and shape of the food plate differed from that used for daily food supply. We presented a maximum amount of food to reduce competition between the individuals within the dyads. Social dominance was assessed through the access order to a single feeder, the monopolization of resources and aggressiveness, as previously done in other species (Boogert et al., 2006; Val-Laill et al., 2008; David et al., 2011). The behaviour of the experimental birds were observed behind a one-way observation screen and video recorded for $2 \mathrm{~min}$; then, the test was terminated. Individuals who did not feed within 2 min were assigned a maximum latency of $120 \mathrm{~s}$. The video recordings were later analysed for latency, total time spent at the feeder, number of visits to the feeder and which individual approach first. Two minutes were set to define foraging behaviours in a social context (Verbeek et al., 1996). All the variables were separately used to assess social dominance. We assumed that the birds reaching the feeder first, spending more time at the feeder and showing a high level of aggressiveness were the dominant birds (Boogert et al., 2006). Each of the twelve dyads experienced two trials in a social feeding contexts, one on day 2 after pairing and another one week later (Figure 1). In both social feeding context trials, individuals were randomly allocated to the dyads with no two individuals being tested together more than once (Schuett 
\& Dall, 2009; David et al., 2011). The sequence in which all individuals were tested was randomized, and the same individuals were not tested together more than once on the same day. Each dyad was kept in a cage equal to the size of the housing cages and under equivalent conditions. Familiar individuals were used to minimize agonistic interactions, which were not often observed in the social feeding context (Schuett \& Dall, 2009; David et al., 2011) and no bird was injured in the course of the trials.

\subsection{Data analysis}

Consistency of both personality traits (exploratory behaviour and neophobia) was measured by calculating behavioural repeatability between the two trials following the Lessells \& Boags (1987) method. We calculated the mean values from both trials for each personality trait, and these mean values were used for further analysis. Because multiple tests were conducted, it was necessary to control for type-I errors. Hence, as an alternative to the Bonferroni correction (Moran, 2003; Nakagawa, 2004), we relied on the procedure introduced by Benjamini \& Hochberg (1995), which is similar to that of Bonferroni but also reduces type-II errors by controlling for the false discovery rate (David et al., 2011). The experiment-wise type-I error was set at 0.05 . Generalized linear models were used to calculate the consistencies of the exploratory behaviour and neophobia trials. Latency to start exploring and feeding latencies were log transformed and used as a response, trial numbers were used as fixed factors and individual identity was used as a random effect (Schuett \& Dall, 2009; Mella et al., 2015; Thomas et al., 2016). The existence of a behavioural syndrome was then measured by the correlation between personality traits. Bivariate correlation was used to examine the correlation between exploratory behaviour and neophobia.

Two generalized linear models were used to measure how individual personality influences foraging behaviour, feeding latency and the total time an individual spent with its partner was used as the response. Trial numbers were fitted as fixed factors, while individual identity and pair identity were fitted as random factors. The total number of visits to the feeder in the social context was calculated using another generalized linear model with Poisson error and log link functions using the Laplace estimation method (Pinheiro $\&$ Bates, 2000; Moretti et al., 2015). Only two-tailed tests were used. The data analysis was performed using SPSS (V. 22). 


\subsection{Ethical note}

The experimental procedures were permitted by the National Animal Research Authority in Northeast Normal University, China (approval number: NENU-20080416) and the Forestry Bureau of Jilin Province of China (approval number: [2006]178).

\section{Results}

\subsection{Repeatability of behaviour and evidence of behavioural syndrome}

Great tits showed significant repeatability in the two trials of exploratory behaviour $(N=24, \beta \pm \mathrm{SE}, 0.69 \pm 0.32, r=0.336, W=4.56, p=0.03)$ and neophobia $(N=24, \beta \pm \mathrm{SE}, 0.12 \pm 0.05, r=0.496, W=6.45, p=0.01)$ trials. Therefore, individual great tits remained consistent in their exploratory behaviours and neophobia over time (repeated tests 1 and 2) in our study.

\subsection{Behavioural correlation}

Individuals who were more exploratory in the exploration test were also bolder in the neophobia test and exhibited shorter feeding latency in the presence of a novel object ( $N=24, r=0.494, p=0.01$ : Figure 2$)$.

\subsection{Influence of personality on social dominance in social feeding context}

Individuals remained consistent in the number of behaviours in the successive trials in the social feeding context: latency to feed, total time spent at

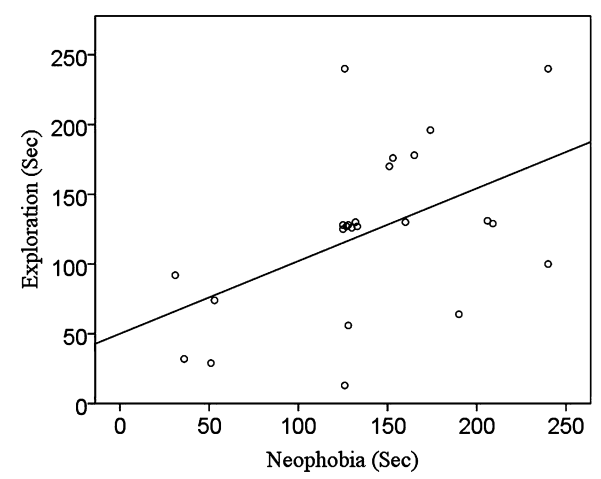

Figure 2. Correlation between exploratory behaviour (latency to start exploring novel environment) and neophobia (latency to approach novel object) generating a behavioural syndrome. 
Table 1.

Repeatabilities of the individual's behaviour in the two successive trials in a social feeding context.

\begin{tabular}{lccccr}
\hline Parameter & df & $W$ & $\beta$ & SE & \multicolumn{1}{c}{$p$} \\
\hline Latency to approach feeders & 22 & 25.46 & 0.422 & 0.019 & $<0.001$ \\
Total time spent at feeders & 22 & 2.753 & 0.434 & 0.056 & 0.009 \\
No of visits at feeder & 22 & 14.374 & 0.514 & 0.034 & $<0.001$ \\
Which individual approach first & 22 & 9.29 & 0.411 & 0.025 & 0.004 \\
\hline
\end{tabular}

the feeder, and total number of visits to the feeders by the individuals was repeatable (Table 1). Proactive males in a social feeding context had decreased feeding latency, spent relatively longer amount of the time at the feeder and made significantly more visits to the feeder than reactive individuals. Proactive individuals approached first the feeder during the social context (Table 1).

\section{Discussion}

We investigated the repeatability and correlational structure of two behavioural traits and the extent to which personality influences dominance in a social feeding context. Our study showed that great tits remained repeatable and consistent in both exploration behaviour and neophobia; the more exploratory individuals were also more bold during the neophobia trials (Figure 2). Both exploratory behaviour and neophobia showed significant correlations, enabling us to sort individuals on a continuum from proactive (explorative, quicker to resume foraging, less neophobic and active birds) to reactive (less explorative, longer to resume foraging, neophobic and less active birds). By definition, animal personality is defined as consistency on long time-scales and several studies have found behaviours to be repeatable across seasons, years and even metamorphosis (Garamszegi et al., 2015; Kaiser et al., 2018). In our study, we cannot affirm true personality that is consistent over time as we only examined two behavioural traits and covered short interval about animal personality.

This repeatability in exploratory behaviour and neophobia in asocial contexts and foraging behaviour in social contexts that is present in the great tit corroborates the findings of former studies that investigated personality differences and consistency in behaviour within and across contexts 
(Beauchamp, 2000; Forstmeier \& Birkhead, 2004; Schuett \& Dall, 2009; Mazué et al., 2015).

Personality has already been found to influence many components of individual behaviour, such as antipredator behaviour (Jones \& Godin, 2009), mating (Wilson et al., 2010) and learning (Boogert et al., 2006). In this study, we showed that personality is associated with social dominance in a social feeding context, a strong predictor of fitness in gregarious bird species (Verhulst \& Salomons, 2004; Schubert et al., 2008). Proactive individuals were more likely to be dominants and spend more time feeding whereas reactive ones tended to be subordinates (Table 1). We would expect dominance to be mainly beneficial during interference competition for food in flocks, irrespective of the birds involved. Our results make sense in relation to the life history productivity hypothesis (Biro \& Stamps, 2008), according to which proactive individuals express behaviours which increase their fitness, associated with a high metabolic rate (Careau et al., 2008). Pro-activity should be related to preferential access to feeding resources, which can be achieved through dominance. In this study, reactive birds could have reached the feeder after dominants ones, but this was not systematically the case. The fact that reactive individuals spent less time feeding which might have been resulted from lower energetic needs rather than from the monopolization of resources by dominants. The present study is based on a former study of great tits (Parus major), where Dingemanse \& de Goede (2004) revealed that relation between personality and dominance is context dependent and varies between studies and across species. For instance opposite results were found in a population of mountain chickadees (Poecile gambeli) (Fox et al., 2009), where low-exploring birds (reactive) were significantly more likely to become dominant in brief pair wise encounters with high exploring birds (proactive). These results leads to the questions of why relation between personality and dominance vary across studies. One possibility is that the relationship between the two variables is context dependent, even within a single population (Dingemanse \& de Goede, 2004).

Overall, our study suggests a multifactorial origin of dominance relationships in great tits. Dominance hierarchies are commonly considered as being determined by either individual abilities ("prior attribute" hypothesis) or social interactions between group members ("social dynamics" hypothesis) (Chase et al., 2002), but one of these hypothesis may have major influence over the other as Whiteman \& Côté (2004) revealed in cleaning gobies 
(Elactinus prochilos) intraspecific competition for resources creates the observed dominance structures and provides support for the role of individual; physical attributes in the formation and maintenance of dominance hierarchies. Evidence shows that both may contribute to the establishment of hierarchies (Chase et al., 2002: Valderrábano-Ibarra et al., 2007) which is likely to be the case in our study.

In conclusion, we were able to document a range of behavioural consistencies in the exploration and neophobia of the great tit, and we have shown that personality is associated with dominance in a social feeding context. We have experimentally demonstrated the influence of dominance on the strength of social association in a key model species for the study of social dynamics (van Oers et al., 2005; Aplin et al., 2013; Snijders et al., 2015, 2017). It is important to understand whether and how individuals can adapt to socially imposed traits, such as dominance, which can have large fitness consequences (Gosler, 1996; Colléter \& Brown, 2011; Gilby et al., 2013). Moreover, insight into how social relations and thus social structures form, are maintained, and change, is crucial for understanding the long-term consequences of the social context, including group positioning and social network connectivity (Romey \& Galbraith, 2008; Oh \& Badyaev, 2010; Formica et al., 2012; Shizuka et al., 2014; Culina et al., 2015; Snijders et al., 2017). Furthermore, understanding the mechanisms of social structuring can be key for identifying keystone individuals and their influence on the social context (Modlmeier et al., 2014). Future research may address the importance of individual personality in shaping hierarchies within groups, by comparing species with contrasted social organizations. We therefore aim to stimulate the future use of novel technologies to advance our understanding of the mechanisms of social structuring in ecology and evolution.

\section{Acknowledgements}

We thank Zheng Han, Jiangping Yu, Ye Gong, Qianxi Fan, Sajid Iqbal and Waqar Shah for the assistance in this work. This work is supported by the National Natural Science Foundation of China (31470458, 31770419 to HW) and the Open Project Program of Jilin Provincial Key Laboratory of Animal Resource Conservation and Utilization (130028823). HW conceived and designed the study. HX and JL sampled bird. NB and YW conducted the experiments. NB, HW and IH analysed the data and wrote the paper. MS proofread and made comments to the manuscript. 


\section{References}

Aplin, L.M., Farine, D.R., Morand-Ferron, J., Cole, E.F., Cockburn, A. \& Sheldon, B.C. (2013). Individual personalities predict social behaviour in wild networks of great tits (Parus major). - Ecol. Lett. 16: 1365-1372.

Archard, G.A. \& Braithwaite, V.A. (2011). Increased exposure to predators increases both exploration and activity level in Brachyrhaphis episcopi. — J. Fish. Biol. 78: 593-601.

Beauchamp, G. (2000). Individual differences in activity and exploration influence leadership in pairs of foraging zebra finches. - Behaviour 137: 301-314.

Benjamini, Y. \& Hochberg, Y. (1995). Controlling the false discovery rate: a practical and powerful approach to multiple testing. - J. Roy. Stat. Soc. B 1: 289-300.

Beránková, J., Veselý, P. \& Fuchs, R. (2015). The role of body size in predator recognition by untrained birds. - Behav. Process. 120: 128-134.

Biro, P.A. \& Stamps, J.A. (2008). Are animal personality traits linked to life-history productivity? - Trends Ecol. Evol. 23: 361-368.

Boissy, A. (1995). Fear and fearfulness in animals. — Q. Rev. Biol. 70: 165-191.

Boogert, N.J., Reader, S.M. \& Laland, K.N. (2006). The relation between social rank, neophobia and individual learning in starlings. — Anim. Behav. 72: 1229-1239.

Brydges, N.M., Colegrave, N., Heathcote, R.J. \& Braithwaite, V.A. (2008). Habitat stability and predation pressure affect temperament behaviours in populations of three spined sticklebacks. — Anim. Ecol. 77: 229-235.

Careau, V., Thomas, D., Humphries, M.M. \& Réale, D. (2008). Energy metabolism and animal personality. - Oikos 117: 641-653.

Chase, I.D., Tovey, C., Spangler-Martin, D. \& Manfredonia, M. (2002). Individual differences versus social dynamics in the formation of animal dominance hierarchies. - Proc. Natl. Acad. Sci. USA 99: 5744-5749.

Clutton-Brock, T.H., O'riain, M.J., Brotherton, P.N., Gaynor, D., Kansky, R., Griffin, A.S. \& Manser, M. (1999). Selfish sentinels in cooperative mammals. — Science 284: 1640-1644.

Colléter, M. \& Brown, C. (2011). Personality traits predict hierarchy rank in male rain bowfish social groups. - Anim. Behav. 81: 1231-1237.

Cresswell, W. (1994). Age-dependent choice of redshank (Tringa totanus) feeding location: profitability or risk? - J. Anim. Ecol. 63: 589-600.

Culina, A., Hinde, C.A. \& Sheldon, B.C. (2015). Carry-over effects of the social environment on future divorce probability in a wild bird population. — Proc. Roy. Soc. Lond. B: Biol. Sci. 282: 20150920.

David, M., Auclair, Y. \& Cézilly, F. (2011). Personality predicts social dominance in female zebra finches, Taeniopygia guttata, in a feeding context. — Anim. Behav. 81: 219-224.

Dingemanse, N.J. \& de Goede, P. (2004). The relation between dominance and exploratory behavior is context-dependent in wild great tits. - Behav. Ecol. 15: 1023-1030.

Dingemanse, N.J. \& Dochtermann, N.A. (2013). Quantifying individual variation in behaviour: mixed-effect modelling approaches. — J. Anim. Ecol. 82: 39-54.

Dingemanse, N.J. \& Wolf, M. (2010). Recent models for adaptive personality differences: a review. — Philos. Trans. Roy. Soc. B: Biol. Sci. 365: 3947-3958. 
Dingemanse, N.J., Both, C., Drent, P.J., Van Oers, K. \& Van Noordwijk, A.J. (2002). Repeatability and heritability of exploratory behaviour in great tits from the wild. - Anim. Behav. 64: 929-938.

Dingemanse, N.J., Wright, J., Kazem, A.J., Thomas, D.K., Hickling, R. \& Dawnay, N. (2007). Behavioural syndromes differ predictably between 12 populations of three spined stickleback. - J. Anim. Ecol. 76: 1128-1138.

Dingemanse, N.J., Kazem, A.J.N., Reale, D. \& Wright, J. (2010). Behavioural reaction norms: animal personality meets individual plasticity. — Trends. Ecol. Evol. 25: 81-89.

Dingemanse, N.J., Dochtermann, N.A. \& Nakagawa, S. (2012). Defining behavioural syndromes and the role of "syndrome" deviation in understanding their evolution. - Behav. Ecvol Sociobiol. 66: 1543-1548.

Drent, P.J., van Oers, K. \& van Noordwijk, A.J. (2003). Realized heritability of personalities in the great tit (Parus major). — Proc. Roy. Soc. Lond. B: Biol. Sci. 270: 45-51.

Formica, V.A., Wood, C.W., Larsen, W.B., Butterfield, R.E., Augat, M.E., Hougen, H.Y. $\&$ Brodie 3rd, E.D. (2012). Fitness consequences of social network position in a wild population of forked fungus beetles (Bolitotherus cornutus). - J. Evol. Biol. 25: 130137.

Forstmeier, W. \& Birkhead, T.R. (2004). Repeatability of mate choice in the zebra finch: consistency within and between females. - Anim. Behav. 68: 1017-1028.

Fox, R.A., Ladage, L.D., Roth II, T.C. \& Pravosudov, V.V. (2009). Behavioural profile predicts dominance status in mountain chickadees, Poecile gambeli. - Anim. Behav. 77: 1441-1448.

Garamszegi, L.Z., Markó, G. \& Herczeg, G. (2012). A meta-analysis of correlated behaviours with implications for behavioural syndromes: mean effect size, publication bias, phylogenetic effects and the role of mediator variables. - Evol. Ecol. 26: 1213-1235.

Garamszegi, L.Z., Markó, G., Szász, E., Zsebők, S., Azcárate, M., Herczeg, G. \& Török, J. (2015). Among-year variation in the repeatability, within-and between-individual, and phenotypic correlations of behaviors in a natural population. - Behav. Ecol. Sociobiol. 69: 2005-2017.

Gilby, I.C., Brent, L.J., Wroblewski, E.E., Rudicell, R.S., Hahn, B.H., Goodall, J. \& Pusey, A.E. (2013). Fitness benefits of coalitionary aggression in male chimpanzees. - Behav. Ecol. Sociobiol. 67: 373-381.

Gosler, A.G. (1996). Environmental and social determinants of winter fat storage in the great tit Parus major. - J. Anim. Ecol. 65: 1-17.

Huntingford, F.A. (1976). The relationship between anti-predator behaviour and aggression among conspecifics in the three-spined stickleback, Gasterosteus aculeatus. - Anim. Behav. 24: 245-260.

Janson, C.H. \& Goldsmith, M.L. (1995). Predicting group size in primates: foraging costs and predation risks. — Behav. Ecol. 6: 326-336.

Jolles, J.W., Boogert, N.J., Sridhar, V.H., Couzin, I.D. \& Manica, A. (2017). Consistent individual differences drive collective behavior and group functioning of schooling fish. —Curr. Biol. 27: 2862-2868. 
Jones, K.A. \& Godin, J.G.J. (2009). Are fast explorers slow reactors? Linking personality type and anti-predator behaviour. — Proc. Roy. Soc. Lond. B: Biol. Sci. 277: 625-632.

Julliard, R., Clavel, J., Devictor, V., Jiguet, F. \& Couvet, D. (2006). Spatial segregation of specialists and generalists in bird communities. — Ecol. Lett. 9: 1237-1244.

Kaiser, A., Merckx, T. \& Van Dyck, H. (2018). Urbanisation and sex affect the consistency of butterfly personality across metamorphosis. - Behav. Ecol. Sociobiol. 72: 188.

Koolhaas, J.M., Korte, S.M., De Boer, S.F., Van Der Vegt, B.J., Van Reenen, C.G., Hopster, H., De Jong, I.C., Ruis, M.A. \& Blokhuis, H.J. (1999). Coping styles in animals: current status in behavior and stress-physiology. - Neurosci. Biobehav. Rev. 23: 925-935.

Krause, J. \& Ruxton, G.D. (2002). Living in groups. — Oxford University Press, Oxford.

Kurvers, R.H., Eijkelenkamp, B., van Oers, K., van Lith, B., van Wieren, S.E., Ydenberg, R.C. \& Prins, H.H. (2009). Personality differences explain leadership in barnacle geese. — Anim. Behav. 78: 447-453.

Kurvers, R.H., Adamczyk, V.M., van Wieren, S.E. \& Prins, H.H. (2010). The effect of boldness on decision-making in barnacle geese is group-size-dependent. — Proc. Roy. Soc. Lond. B: Biol. Sci. 278: 2018-2024.

Lessells, C.M. \& Boag, P.T. (1987). Unrepeatable repeatabilities: a common mistake. — Auk 116: 21-23.

Lima, S.L. \& Bednekoff, P.A. (1999). Temporal variation in danger drives antipredator behavior: the predation risk allocation hypothesis. - Am. Nat. 53: 649-659.

Marchetti, C. \& Drent, P.J. (2000). Individual differences in the use of social information in foraging by captive great tits. - Anim. Behav. 60: 131-140.

Mazué, G.P., Dechaume-Moncharmont, F.X. \& Godin, J.G. (2015). Boldness-exploration behavioral syndrome: interfamily variability and repeatability of personality traits in the young of the convict cichlid (Amatitlania siquia). — Behav. Ecol. 26: 900-908.

Mella, V.S., Ward, A.J., Banks, P.B. \& McArthur, C. (2015). Personality affects the foraging response of a mammalian herbivore to the dual costs of food and fear. - Oecologia 177: 293-303.

Michelena, P., Sibbald, A.M., Erhard, H.W. \& McLeod, J.E. (2008). Effects of group size and personality on social foraging: the distribution of sheep across patches. - Behav. Ecol. 20: 145-152.

Modlmeier, A.P., Keiser, C.N., Watters, J.V., Sih, A. \& Pruitt, J.N. (2014). The keystone individual concept: an ecological and evolutionary overview. - Anim. Behav. 89: 53-62.

Moran, M.D. (2003). Arguments for rejecting the sequential Bonferroni in ecological studies. — Oikos 100: 403-405.

Moretti, L., Hentrup, M., Kotrschal, K. \& Range, F. (2015). The influence of relationships on neophobia and exploration in wolves and dogs. - Anim. Behav. 107: 159-173.

Nakagawa, S.A. (2004). A farewell to Bonferroni: the problems of low statistical power and publication bias. - Behav. Ecol. 15: 1044-1105.

Oh, K.P. \& Badyaev, A.V. (2010). Structure of social networks in a passerine bird: consequences for sexual selection and the evolution of mating strategies. - Am. Nat. 176: E80-E89. 
Pike, T.W., Samanta, M., Lindström, J. \& Royle, N.J. (2008). Behavioural phenotype affects social interactions in an animal network. - Proc. R. Soc. Lond. Biol. 275: 2515-2520.

Pinheiro, J.C. \& Bates, D.M. (2000). Mixed-effects models in S and S-plus. - Springer, New York, NY.

Reale, D., Reader, S.M., Sol, D., McDougall, P.T. \& Dingemanse, N.J. (2007). Integrating animal temperament within ecology and evolution. — Biol. Rev. 82: 291-318.

Romey, W.L. \& Galbraith, E. (2008). Optimal group positioning after a predator attack: the influence of speed, sex, and satiation within mobile whirligig swarms. — Behav. Ecol. 19: 338-343.

Sasaki, T., Mann, R.P., Warren, K.N., Herbert, T., Wilson, T. \& Biro, D. (2018). Personality and the collective: bold homing pigeons occupy higher leadership ranks in flocks. Philos Trans. Roy. Soc. Lond. B: Biol. Sci. 373: 20170038.

Schubert, K.A., Mennill, D.J., Ramsay, S.M., Otter, K.A., Ratcliffe, L.M. \& Kraus, C. (2008). Between-year survival and rank transition in male black-capped chickadees (Poecile atricapillus): a multisite modelling approach. - Auk 125: 629-636.

Schuett, W. \& Dall, S.R. (2009). Sex differences, social context and personality in zebra finches, Taeniopygia guttata. - Anim Behav. 77: 1041-1050.

Shizuka, D., Chaine, A.S., Anderson, J., Johnson, O., Laursen, I.M. \& Lyon, B.E. (2014). Across-year social stability shapes network structure in wintering migrant sparrows. Ecol. Lett. 17: 998-1007.

Sih, A. \& Bell, A.M. (2008). Insights for behavioral ecology from behavioral syndromes. Adv. Stud. Behav. 38: 227-281.

Sih, A., Kats, L.B. \& Maurer, E.F. (2003). Behavioural correlations across situations and the evolution of antipredator behaviour in a sunfish-salamander system. - Anim. Behav. 65: 29-44.

Sih, A., Bell, A.M. \& Johnson, J.C. (2004a). Behavioral syndromes: an ecological and evolutionary overview. - Trends Ecol. Evol. 19: 372-378.

Sih, A., Bell, A.M., Johnson, J.C. \& Ziemba, R.E. (2004b). Behavioural syndromes: an integrative overview. - Q. Rev. Biol. 79: 241-277.

Sih, A., Mathot, K.J., Moirón, M., Montiglio, P.O., Wolf, M. \& Dingemanse, N.J. (2015). Animal personality and state-behaviour feedbacks: a review and guide for empiricists. Trends. Ecol. Evol. 30: 50-60.

Smith, B.R. \& Blumstein, D.T. (2008). Fitness consequences of personality: a meta-analysis. - Behav. Ecol. 19: 448-455.

Snijders, L., Naguib, M. \& van Oers, K. (2017). Dominance rank and boldness predict social attraction in great tits. - Behav. Ecol. 28: 398-406.

Snijders, L., van der Eijk, J., van Rooij, E.P., De Goede, P., van Oers, K. \& Naguib, M. (2015). Song trait similarity in great tits varies with social structure. - PLoS ONE 10: e0116881.

Svensson, L. (1992). Identification guide to European Passerines. - Naturhistoriska Riskmuseet, Stockholm.

Thomas, P., Herrel, A., Hardy, I., Aujard, F. \& Pouydebat, E. (2016). Exploration behavior and morphology are correlated in captive gray mouse lemurs (Microcebus murinus). Int. J. Primatol. 37: 405-415. 
Val-Laillet, D., de Passillé, A.M., Rushen, J. \& von Keyserlingk, M.A.G. (2008). The concept of social dominance and the social distribution of feeding related displacements between cows. - Appl. Anim. Behav. Sci. 111: 158-172.

Valderrábano-Ibarra, C., Brumon, I. \& Drummond, H. (2007). Development of a linear dominance hierarchy in nestling birds. - Anim. Behav. 74: 1705-1714.

van den Bos, R., Homberg, J. \& de Visser, L. (2013). A critical review of sex differences in decision-making tasks: focus on the Iowa Gambling Task. - Behav. Brain. Res. 238: 95-108.

Van Oers, K., Drent, P.J., De Jong, G. \& Van Noordwijk, A.J. (2004a). Additive and nonadditive genetic variation in avian personality traits. - Heredity 93: 496-503.

Van Oers, K., de Jong, G., Drent, P.J. \& van Noordwijk, A.J. (2004b). A genetic analysis of avian personality traits: correlated, response to artificial selection. - Behav. Genet. 34: 611-619.

Van Oers, K., Drent, P.J., De Goede, P. \& Van Noordwijk, A.J. (2004c). Realized heritability and repeatability of risk-taking behaviour in relation to avian personalities. - Proc. Roy. Soc. Lond. B: Biol. Sci. 271: 65-73.

Van Oers, K., Klunder, M. \& Drent, P.J. (2005). Context dependence of personalities: risktaking behavior in a social and a nonsocial situation. - Behav. Ecol. 16: 716-723.

Verbeek, M.E., Boon, A. \& Drent, P.J. (1996). Exploration, aggressive behaviour and dominance in pair-wise confrontations of juvenile male great tits. - Behaviour 133: 945-963.

Verhulst, S. \& Salomons, H.M. (2004). Why fight? Socially dominant jackdaws, Corvus monedula, have low fitness. - Anim. Behav. 68: 777-783.

Vickery, W.L., Giraldeau, L.A., Templeton, J.J., Kramer, D.L. \& Chapman, C.A. (1991). Producers, scroungers, and group foraging. - Am. Nat. 137: 847-863.

Webster, M.M. \& Ward, A.J.W. (2011). Personality and social context. - Biol. Rev. 86: 759-773.

Whiteman, E.A. \& Côté, I.M. (2004). Dominance hierarchies in group-living cleaning gobies: causes and foraging consequences. - Anim. Behav. 67: 239-247.

Williams, L.J., King, A.J. \& Mettke-Hofmann, C. (2012). Colourful characters: head colour reflects personality in a social bird, the Gouldian finch, Erythrura gouldiae. - Anim. Behav. 84: 159-165.

Wilson, A.D., Whattam, E.M., Bennett, R., Visanuvimol, L., Lauzon, C. \& Bertram, S.M. (2010). Behavioral correlations across activity, mating, exploration, aggression, and antipredator contexts in the European house cricket, Acheta domesticus. - Behav. Ecol. Sociobiol. 64: 703-715.

Wilson, D.S. (1998). Adaptive individual differences within single populations. - Phil. Trans. Roy. Soc. B: Biol. Sci. 353: 199-205.

Wolf, M. \& Weissing, F.J. (2012). Animal personalities: consequences for ecology and evolution. — Trends Ecol. Evol. 27: 452-461. 